\title{
Wissenschaftspreis 2014 - Ausschreibung
}

Die Deutsche Gesellschaft für Ultraschall in der Medizin (DEGUM) vergibt einen Preis für eine hervorragende wissenschaftliche Arbeit auf dem Gebiet des medizinischen Ultraschalls. Der Preis ist mit $€ 5000$,- dotiert und kann geteilt werden. Es können sich jüngere Wissenschaftler (Geburtsjahr 1974 oder jünger) bewerben, die mehrere, richtungsweisende Arbeiten zu einem Thema publiziert haben. Es kann auch eine Habilitationsschrift eingereicht werden, sofern diese auf hochrangig publizierten Originalarbeiten beruht.

Der Wissenschaftsbeirat der DEGUM bewertet die Arbeit auf der Grundlage von zwei Gutachten und entscheidet über die
Preisvergabe, seine Entscheidung ist endgültig und nicht anfechtbar.

Die formlose Bewerbung ist auf elektronischem Weg bis zum 31.05.2014 an die DEGUM-Geschäftsstelle zu richten. Der Bewerbung sollen die relevanten Publikationen, ein Lebenslauf des Bewerbers sowie eine kurze Zusammenfassung der Arbeiten (nicht mehr als drei DIN A4-Seiten), jeweils in digitaler Form und ebenfalls auf elektronischem Weg, beigefügt werden.

Die Preisverleihung erfolgt während des Dreiländertreffens 2014 in Innsbruck (29.-31.10.2014). Die persönliche Anwesenheit der Preisträgerin/des Preisträgers ist obligat. Von ihr/ihm wird erwartet, dass sie/er die mit dem DEGUM-Preis ausgezeichnete Arbeit während des Dreiländertreffens in Form eines Vortrags vorstellt. Die Preisträgerin/der Preisträger ist Gast der DEGUM, seine Reise- und Übernachtungskosten sowie die Teilnahmegebühr werden übernommen.

München im Januar 2014

Dr. S. Nöldeke, Präsident der DEGUM Prof. Dr. M. Görtler, Sekretär der DEGUM 